\title{
Psychological, Behavioral, and Economic Perspectives on Corruption
}

\section{Qingguo $\mathrm{Ma}^{*}$ and Min Yan}

Neuromanagement Lab, Zhejiang University, P.R. China

*Corresponding author: Qingguo Ma, Neuromanagement Lab, School of Management, Zhejiang University, 38 Zheda Road, 310027 Hangzhou, China, Tel: +86-571-87952790

\begin{abstract}
With the development and transformation of China's economy, "anti-corruption" has become the top priority of the Communist Party of China in recent years. Corruption is a kind of unethical behavior that the public power loss the public nature because of private using, it deviates from the value of public power and the goals of the value. Here, we review both experimental evidences documenting acts of small corruption and recent evolutionary cognitive models based on surveys of corruption. These studies show that corruption and the crime of corruption is a phased development process based on psychological development theory and game theory. This unethical behavior can be a crime by the unconscious cognitive processes begins with the simple reciprocity behavior to slip into large illegal acts or be a transition process by the subject of corruption from the initial compliance with corrupt group of standards or requirements to becoming unconscious acts of corruption or norm. These researches present different commentary and results, and sometimes even contradictory views.
\end{abstract}

\section{Keywords}

Cognitive science, Behavioral economics, Corruption, Corrupt criminal, Unethical behavior

\section{Introduction}

Corruption, a common system problem, is the most common phenomenon especially in the developing and transforming of social system $[1,2]$. With the continuous development of China's economy, efforts of economic system reform have been stepped up. While China is experiencing unprecedented economic development, there is inevitably experiencing corruption in the ensuing that have become increasingly rampant in the government and enterprises and institutions at all levels as white-collar economic crime [1,3]. In China, economic crime and corruption crimes have been widely concerned, anti-corruption is a focus issue of the work of the government since the reform and opening up, especially in recent years. The data showed that from November 2007 to June 2012, the discipline inspection and supervision organs filed with 643759 cases, closed 639068 cases, give disciplinary sanctions to 668429 persons, 24584 persons as suspected of a crime were transferred to judicial organs for handling, the investigating cases of commercial bribery were 81391, the amount involved in these cases was 222.03 billion yuan (close to 3.38 billion US dollar) [4]. In 2014, the government announced to be used without penalty area, full coverage, zero tolerance attitude, and severely punish corrupt elements.

From the individual level, the corruption is a kind of unethical behavior, and the economic crimes caused by corruption (Crime of corruption) is often a kind of behavior that public power loss the public nature because of the non-public use, it deviates from the foundation value of the public power and the goal of the value [5]. The crime of corruption is described as one or a series of implementation of intentional crime of a government officer that "embezzles or misappropriates to violate the property" or "trading the power" or "abuse of power" and so on [6].

The whole process on the tiny unconscious corruption rise to criminal behavior is an issue that academic researchers pay close attention to research from the aspects of jurisprudence, criminology, social science, psychology and so on. These important social science disciplines in commentary corruption and the crime of corruption has many different on main theoretical mechanism, many theoretical assumptions are based on rational man, such as economic man hypothesis, Becker 
theory hypothesis. However, for psychology in research of unethical behavior, it found that unethical behavior was not always rational choice [7]. It is obviously different results of different social science research, sometimes even have conflicting views.

\section{Corruption and Crime of Corruption}

Corruption is recognized as a kind of typical unethical behavior, Aristotle, Machiavelli and Meng Desi sound it as a signal of moral decay in the society. Corruption, a harmful social phenomenon and criminal behavior, defined on Roman law as a kind of behavior that public officials take or ask for some benefits to impact his own behavior and options. However, because of its changing form and its multilayer during the development process, it is hard to give a clear definition [8].

Three typical types of corrupt criminal acts committed by public officials were described according to "the United Nations Convention against corruption" [6]:

- Embezzlement, misappropriation or other means of infringing upon property. Public officer for their own interests or other personnel or organizational interests, corrupt, misappropriate or any other means to infringe upon any entrusted property or total capital, private capital, public vouchers, private vouchers or any other valuables.

- Influence transaction. Public officer or any other person get any undue benefit directly or indirectly for himself or any other person, as the officer or the other personnel abuse his or her actual impact or influence obtain any unfair advantage condition from administrative department or public authority of a Contracting State.

- Abuse of power. Public officers violate the law in the performance of their duties to implement or not to carry out an act due to obtain unjustified benefits for himself or other personnel or entity.

\section{Researches on Cognitive Process of Corruption and Crime of Corruption}

According to the literature of cognitive researches on corruption, the psychological processing of corrupt criminals can be divided into two types: one is the processing from inward to external, can be used "morality decay" to describe, the criminal always begins from small unconscious corruption, gradually slip into the large illegal acts. The whole process is "impulse" in the role; the other is the processing from external to inward, the criminal start from the initial compliance with the standards or needs of the corrupt group, eventually have an unconscious or normal behavior towards corruption, the whole process is the distortion or destruction of "integrity" by "obedience" [8,9].

Based on moral psychological literature, the process of corruption from internal to external can be explained by bounded ethicality [10], ethical fading [11], and moral seduction [12]. A large number of social psychology researches advised that from the aspect of individual psychology there is general decision making bias and framing effects to support and explain the whole process more basically, specifically there are three paths of this psychological process: self-serving bias, inability to judge outcomes and framing effects [8].

A large number of empirical evidences showed that persons with high social status (such as the authorities) are often prone to self-interest $[9,13,14]$. Moreover, human prefer to choose those decision scheme with obvious results in decision-making, the most corrupt behavior can bring benefits, which is spot, intuitive and can be determined (i.e., increase direct personal property, access to direct political interests and so on), otherwise most corrupt behavior risk is more hidden and difficult to determine in a long period of time (i.e., punished, exposure and potential risk for criminal liability). Therefore, in the state of nature human often make unconscious choice of corruption [15-17]. In addition, Kahneman (1979) proposed framing effect of decision, namely at uncertain conditions in income situation (positive framing) people prefer to deterministic choice, while people's choice exist risk preference in loss situation (negative framing). A large number of empirical studies have proved that corrupt criminals tend to exhibit the characteristics of risk preference [9].

In the researches on individual corrupt criminals, some researchers put forward specific personality traits relate to the occurrence of corruption, after investigated personality traits of this kind of crime criminal they result that such criminals tend to have selfishness, greed and lust, consciousness of strongly carving rights or power, inhibited guilt on their own corruption, and low integrity characteristics. Whether the personality trait is the core of the crime of corruption is still controversial. In this paper, through interpreted three paths on psychological process of corruption from the internal to external, we extend to support the view of Sutherland that there is no relationship between personality traits and economic crime [18]. The personality traits of the corruption criminals mentioned before, is further evidence that the crime of corruption occurrence in the unconscious state by the petty corruption gradually slide into the abyss of crime of corruption, through these three paths of the mental processing. These traits are just the results that the changes of individual criminals' cognition, evaluation or sensory are probed after the occurrence of acts. Certainly, the whole process is a natural occurrence process without the intervention of the outside world, that is, occurred without supervision and environmental moral constraints. However, some researchers pointed that economic crime is not from the physical or psychological characteristics of criminals, but from the individual's context and social ties with the organization [19]. 
The view of Alalehto described another type of mental processing of the occurrence and development of corruption, which was the process of corruption from external to internal. This process is driven by two external forces from the outside and within the role of the individual, so that it tends to corrupt behavior. One force comes from bending over right, and the other is from the contract in the process of socialization.

Some studies showed that the key factors influencing unethical behavior are behavioral regulation $[20,21]$. We can think that if a person is put in the following situation, in which an authority indicates him to involve in a number of acts of corruption, the person may simply act, and believes that he is just a loyal subordinate and do not take into account the legality and morality of the act itself. In addition, Sutherland (1939) also proposed a social learning theory of criminal behavior, in the process of interaction between the individual and peer, corrupt behavior of peer will encourage and rationalize corruption. Furthermore, there are experiments to prove that when the authority effect and peer effects worked on the corrupt behavior at the same time, their influence will be amplified [22], in fact this is the process of individual socialization.

In that way, how to make the corrupt behavior norms to become their own social behavior norms during the process of socialization? In the discussion of corruption and organization attitude to the corruption, Fein and Weibler used related theories of moral development of Kohlberg [23], proposed that corruption or unethical behavior existed a phased development process, that low level of behaviors and their corresponding state were coordinated and integrated into a high level of behavior through accumulation of quantity, as changes in the behavior of the individual is also accompanied by changes in the attitude $[7,24]$. According to the description of the corrupt behavior, the individual can be regarded as the "corruption" just as enter the stage of generalization, in which individual clarify social norms (such as honesty, to provide fair services) and roles (such as leadership, subordinates) and ignore the contradiction between role and social norms. This is the focus of most discussions - where did the corruption start?

Researches on Corruption and Crime of Corruption from the Perspective of Behavioral Economics and Game Theory

Many economic and social researchers use the basic theory of economics to discuss the causes of corruption and the occurrence of corruption crime. Economists explain the behavior of corruption of public officials by economic man hypothesis, they pointed that "the government officials are economic man, that is the pursuit of maximizing their own interests in the specific system constraints" [25]. Famous economist Becker (1968) announced that "cost-benefit" model of the crime is also used for interpretation of the crime of corruption, for example public officials in the implementation of economic crimes can get three kinds of benefits: directly acquired material interests from the crime, political interests and psychological gratification caused by the crime; simultaneously, corruption consume three kinds of costs: the direct cost, opportunity cost and penalty cost [26]. Under normal circumstances, behavior does not occur when there is a balance between the cost and income. However, when any kind of cost reduces, it will lead to the occurrence of behavior. Wu implemented theory of Rent Seeking to analysis opportunities for corruption and infer the source of corruption that the occurrence of corruption is most officials seek the monetary value of the lease for authority [27].

Behavioral economists simulate the occurrence of bribery (typical corrupt behavior) in a laboratory environment, which has been confirmed that influence bribery law enforcement system by the top-down [28] and bottom-up [29-31], and effectiveness of different monetary reward [32], and also prove that bribery occurred in the presence of gender [33-35] and cultural differences $[28,31,36,37]$. In addition, there is experimental study of repetitive bribery game reveal that and the intrinsic motivation related to the violations have a significant impact on decision-making of corruption, and there is no evidence that the framing effect and external effect influence decision-making of corruption $[29,38]$. In the simple, disposable bribery game, it found that breaking social norms and/or hurt others moral cost significantly influences bribery decision, there was no relationship between corrupt behavior decision and trust and reciprocity [36].

In sum, the literature of social psychology clarifies psychological processes play into the dynamic nature of corruption, while computer simulation of small corruption in the research of behavioral economics lost the sight of the whole psychological process of subject of the crime. In the process of occurrence and development of the whole criminal behavior, it involves the complicated mental process such as awareness, intrinsic motivation, socialization, judgment and decision making. Thus, although there is considerable research on the process of corruption, the conceptual and methodological limitations of the extant research make it difficult to make definitive conclusions and a clear model regarding the dynamic process of corruption.

\section{References}

1. Yu O (2008) Corruption in China's economic reform: A review of recent observations and explanations. Crime, Law and Social Change 50: 161-176.

2. Zimring FE, Johnson DT (2008) Law, society, and capital punishment in Asia. Punishment \& Society 10: 103-115.

3. Ghazi-Tehrani AK, Pushkarna N, Shen P, Geis G, Pontell HN (2013) White-collar and corporate crime in China: A comparative analysis of enforcement capacity and non-is- 
sue making. Crime Law Soc Change 60: 241-260.

4. Report on the work of the CPC Central Commission for discipline inspection at the 18th National Congress of the CPC.

5. Sun HS (2006) Control theory of corruption crime. Doctoral Dissertation of Criminal Law, Jilin University.

6. Webb P (2005) The United Nations convention against corruption: Global Achievement or Missed Opportunity? Journal of International Economic Law 8: 191-229.

7. Fein E, Weibler J (2014) Review and shortcomings of literature on corruption in organization in offering a multi-faceted and integrative understanding of the phenomenon. Behavioral Development Bulletin 19: 67-77.

8. Moore C (2009) Psychological processes in organizational corruption. In: Cremer DD, Psychological Perspectives on Ethical Behavior and Decision Making. Information Age Publishing Press, USA, 35-71.

9. Bucy PH, Formby EP, Raspanti MS, Rooney KE (2008) Why do they do it? The motives, mores, and charcter of white collar criminals. St. John's Law Review 82: 401.

10. Chugh D, Bazerman MH, Banaji MR (2005) Bounded ethicality as a psychological barrier to recognizing conflicts of interest. In: Moore DA, Cain DM, Loewenstein G, Bazerman $\mathrm{MH}$, Conflicts of interest: Challenges and solutions in business, law, medicine, and public policy. Cambridge University Press, New York, USA, 74-95.

11. Tenbrunsel AE, Messick DM (2004) Ethical fading: The role of self-deception in unethical behavior. Social Justice Research 17: 223-236.

12. Moore DA, Tetlock PE, Tanlu L, Bazerman MH (2006) Conflicts of interest and the case of auditor independence: Moral seduction and strategic issue cycling. Academy of Management Review 31: 10-29.

13. De Cremer D, Van Dijk E (2005) When and why leaders put themselves first: Leader behavior in resource allocations as a function of feeling entitled. European Journal of Social Psychology 35: 553-563.

14. Piff PK, Stancato DM, Cote S, Mendoza-Denton R, Keltner D (2012) Higher social class predicts increased unethical behavior. PNAS 109: 4086-4091.

15. Tversky A, Kahneman D (1981) The framing of decisions and the psychology of choice. Science 211: 453-458.

16. Tversky A, Kahneman D (1992) Advances in prospect theory: Cumulative representation of uncertainty. Journal of Risk and Uncertainty 5: 297-323.

17. Tversky A, Wakker $P$ (1995) Risk attitudes and decision weights. Econometrica 63: 1255-1280.

18. Sutherland EH (2010) White-collar criminality. Philosophical Alternatives Journal 5: 1-12.

19. Alalehto T (2003) Economic crime: Does personality matter? International Journal of Offender Therapy \& Comparative Criminology 47: 335-355.

20. Baumhart RC (1961) How ethical are businessmen? Harvard Business Review 39: 6-176.

21. Brenner SN, Molander EA (1977) Is the ethics of business changing? Harvard Business Review 55: 57-71.

22. Jones DG, Kavanagh JP (1984) Business, religion, and ethics: Inquiry and encounter. Business \& Professional Ethics Journal 2: 73-77.
23. Kohlberg L (1969) Stage and sequence. The cognitive developmental approach to socialization. In: DA Goslin, Handbook of socialization theory. Chicago, USA, 347-480.

24. Fein E, Weibler J (2014) Cognitive basis for corruption and attitudes towards corruption in organizations viewed from a structuralist adult developmental meta-perspective. Behavioral Development Bulletin 19: 78-94.

25. Rose-Ackerman P (1996) The political economy of corruption-causes and consequences. General Information 45: 561-562.

26. Gary Becker (1968) Crime and punishment: An economic approach. The Journal of Political Economy 76: 169-217.

27. Wu JL (2002) Thinking on economics of corruption and anti-corruption. Anti-corruption Guard 11: 10-15.

28. Abbink K, Irlenbusch B, Renner E (2002) An experimental bribery game. Journal of Law, Economics, and Organization 18: 428-454.

29. Cameron L, Chaudhuri A, Erkal N, Gangadharan L (2009) Propensities to engage in and punish corrupt behavior: Experimental evidence from Australia, India, Indonesia and Singapore. Journal of Public Economics 93: 843-851.

30. Banuri S, Eckel C (2012) Experiments in culture and corruption: A review. Research in Experimental Economics.

31. Serra D (2012) Combining top-down and bottom-up accountability: Evidence from a bribery experiment. Journal of Law Economics \& Organization 28: 569-587.

32. Armantier O, Boly A (2012) On the external validity of laboratory experiments on corruption. New Advances in Experimental Research on Corruption. Research in Experimental Economics 15: 117-144.

33. Rivas MF (2013) An experiment on corruption and gender. Bulletin of Economic Research 65: 10-42.

34. Alatas V, Cameron L, Chaudhuri A, Erkal N, Gangadharan $L$ (2009) Subject pool effects in a corruption experiment: A comparison of Indonesian public servants and Indonesian student. Exp Econ 12: 113-132.

35. Alatas V, Cameron L, Chaudhuri A, Erkal N, Gangadharan $L$ (2009) Gender, culture, and corruption: Insights from an experimental analysis. Southern Economic Journal 75 : 663-680.

36. Banuri S, Eckel CC (2012) Experiments in culture and corruption: A review. In: D Serra, L. Wantchekon, New advances in experimental research on corruption. Emerald, UK.

37. Barr A, Serra D (2008) The effects of externalities and framing on bribery in a petty corruption experiment. Experiment Economics 12: 488-503.

38. Abbink K, Hennig-Schmidt H (2006) Neutral versus loaded instructions in a bribery experiment. Experiment Economics 9: 103-121. 